\title{
Deseja-se mulher Do texto ao palco
}

\section{Sílvia Laureano Costa}

É possivel recuperar-se o percurso de um espectáculo de teatro, desde os esboços do texto até à sua estreia em cena? Pensei nisto quando tinha nas mãos a primeira edição de Deseja-se mulher de Almada Negreiros, saída em 1959. Até chegar a livro, Deseja-se mulher sofreu um processo de escrita e reescrita, como o próprio Almada revelou num ensaio publicado na revista Sudoeste 2 e como o testemunham centenas de documentos conservados no espólio do autor?.

Eu sabia que a peça tinha sido levada à cena pela primeira vez em Novembro de 1963 na Casa da Comédia, com encenação de Fernando Amado. Pouco mais. E queria conhecer o caminho que aquele texto fizera até chegar às tábuas. De que forma? De um espectáculo podem conservar-se elementos ligados à cenografia, adereços e figurinos (maquetas, cenários, croquis, guarda-roupa, objectos...); gravar memórias dos ensaios e das representações; recuperar as expectativas dos jornalistas e as reacções dos críticos na imprensa; guardar convites, programas, fotografias, vídeos - portanto, no fundo, é possivel reunir muito do que está, ou esteve, ligado à concepção de um espectáculo de teatro e tentar recriar o que, por definição, é efémero.

Faltava fazer isso em relação a Deseja-se mulher: desenterrar papéis, reconstituir memórias de quem esteve envolvido no espectáculo, delimitar um percurso possivel do texto-livro ao texto-palco. Procurei fazê-lo; e, mesmo não tendo esgotado as fontes de investigação, o resultado foi um trabalho académico com alguma extensão, realizado no âmbito do Seminário de Investigação sobre Autores Modernistas, orientado pelo Professor Doutor Fernando Cabral Martins, no Doutoramento em Estudos Portugueses da Faculdade de Ciências Sociais e Humanas da Universidade Nova de Lisboa, no ano lectivo de 2010/2011. Reuni todos os materiais existentes: o programa do espectáculo, algumas das fotografias de José Marques (que permitem visualizar cenários e figurinos), os recortes de imprensa da época, memórias e relatos de três intervenientes no espectáculo, as actrizes Fernanda Lapa e Maria do Céu Guerra e o (então) cenógrafo e figurinista,
Vitor Silva Tavares. Como facilmente se compreenderá, os testemunhos orais de quem conviveu e trabalhou com Almada Negreiros e com Fernando Amado são uma fonte privilegiada de memórias ligadas à concepção e criação deste espectáculo, mas também um precioso contributo para entender o conceito de teatro destes dois criadores.

Nestas pesquisas, deparei-me ainda com o dactiloscrito da peça no arquivo da Torre do Tombo, na série de Processos de Censura a Peças de Teatro, do subfundo da DirecçãoGeral dos Serviços de Espectáculos, do Secretariado Nacional de Informação. É, assim, possivel verificar que o texto Deseja-se mulherfoi submetido à leitura dos censores, como era de regra, tendo sido aprovado com alguns cortes. A leitura deste documento permite ter uma ideia do que, na época, era considerado subversivo ou imoral... Aqui, deixo apenas algumas linhas que permitem voltar a olhar para Deseja-se mulher e percorrer um trajecto, desde a sua existência em livro até à sua presença em palco, detendo-me um pouco nas objecções colocadas pela censura. Pretendo, com isto, contribuir para a fixação de informações e de memórias - com as quais, se faz também a história do espectáculo em Portugal.

\section{0 texto em livro}

Deseja-se mulher, de José de Almada Negreiros, chega às bancas em 1959. Na capa lê-se o nome do autor, o título a negro e a encarnado, o desenho da fórmula " $1+1=1 "$, assinado por Almada com o "d" de haste longa, e a indicação de "espectáculo em 3 actos e 7 quadros". No interior, a abrir cada quadro e antes de fechar a peça, há um desenho a traço preto que estabelece um diálogo evidente com as didascálias. As oito ilustrações funcionam como maquetas, fixando as linhas do ambiente visual sugeridas pelo texto. É o Almada a criar a duas mãos - o escritor e o pintor juntos - e a contribuir para a concepção de teatro como arte colaborativa, um espaço onde as artes se cruzam e onde a criação individual encontra o seu lugar no colectivo: "É efectivamente no Teatro que se reúnem todas as outras artes. Entendamos bem: não é o Teatro que as reúne, elas é que se reúnem no Teatro" (Negreiros 1935: 134). Almada
10 espólio conjunto de Almada Negreiros e Sarah Affonso está a ser tratado no âmbito do projecto Modernismo Online (IELTFCSH-UNL), financiado pela Fundação para a Ciência e a Tecnologia e pela Fundação Calouste Gulbenkian.

Silvia Laureano Costa é doutoranda em Estudos Portugueses na FCSH-UNL e desenvolve investigação com vista à sua tese sobre "O teatro e a estética teatral de Almada Negreiros".

É investigadora no projecto Modernismo online: Arquivo virtual da geração de Orpheu, financiado pela FCT e pela FCG, e dedicado à inventariação, preservação e divulgação de espólios de autores modernistas, trabalhando ai directamente com os espólios de José de Almada Negreiros e de Sarah Affonso. 
${ }^{2}$ Vitor Silva Tavares pediu a Almada para escrever essa história e integrou o texto manuscrito no programa do espectáculo Deseja-se mulher, na Casa da Comédia, em 1963. In Conversa com Vitor Silva Tavares (Silvia Laureano Costa, entrevistadora), Lisboa, 23 de Junho de 2011.
Negreiros defende que "o Teatro é nosso, dos pintores, o escaparate das artes plásticas" (Negreiros 1992b: 163) e que, para além das artes plásticas, o teatro precisa de todas as outras artes para existir de forma total:

E, dizia-me o pintor, não é pelo assunto que gosto da obra, é por uma ligação de tudo o que em cena põem diante dos meus sentidos. Se fosse surdo e seguisse a acção só vendo, gostava da obra. Em pintura e nas artes plásticas a acção é só vendo. Na música é só ouvindo. No teatro é com todos os sentidos. (Negreiros 1992b: 164)

Seguindo a perspectiva de Almada, se o "assunto" por si só não faz a peça e se o teatro, para acontecer, precisa da "ligação de tudo", de "todos os sentidos", então, um texto dramático como Deseja-se mulher, que é publicado sem que, anteriormente, tivesse sido levado à cena, só se torna verdadeiro teatro quando deixar o papel e for transposto para o palco. E é talvez essa a razão por que o autor, durante tantos anos, adia a publicação do texto completado em 1928.

Com o livro, foram divulgados o texto da peça e os desenhos para os cenários. Mas, insiste-se, falta ainda fazer-se teatro ou "espectáculo" - que para o autor é uma e a mesma coisa: "o teatro é essencialmente espectáculo. A palavra espectáculo está estreitamente ligada à palavra teatro" (Negreiros s/d: 2). E é precisamente à palavra "espectáculo" que Almada recorre para categorizar Deseja-se Mulher, criando, uma vez mais, a ideia de unidade na concepção da arte, traduzida pela fórmula, aparentemente simples, "1+1=1".

Desconhece-se o que o leva a editar Deseja-se mulher sem o ter visto em palco (é a primeira vez que acontece com um texto seu para teatro; Antes de começar sai apenas em 1956, por ocasião da segunda encenação de Fernando Amado), mas sabe-se que, em 1932, quando chegou de Madrid com a peça na bagagem, fala com pessoas ligadas ao teatro, entre as quais Amélia ReyColaço e Robles Monteiro, na tentativa de ver encenada esta ou uma outra obra sua, S.O.S. - sem quaisquer resultados. Almada acredita que, "se houvesse um público capaz de aguardar curioso o que o artista se meteu a decifrar" (Negreiros 1993: 152), estas peças teriam subido imediatamente o palco. Isso não acontece.

Parece que se cumpria a premonição de Garcia Lorca - que Almada conta a Vitor Silva Tavares por altura da preparação da estreia do espectáculo na Casa da Comédia e que o cenógrafo e figurinista da peça aproveita para incluir no programa2: "Quando li Deseja-se mulhere S.O.S. em Madrid (1928) Frederico Garcia Lorca disse: Dou-te trinta anos para que te entendam". Mas, afinal, foram precisos mais do que trinta anos para o público assistir ao espectáculo: só em 1963 é que Deseja-se mulher foi aplaudido - muito tempo após a sua escrita e quatro anos depois da sua publicação em livro.

\section{0 texto aprovado com cortes da censura}

Almada Negreiros considera que o teatro deve chegar a todos os espectadores: "Nenhuma arte tem de falar para todos a não ser o teatro" (Negreiros 2006: 101). Para isso, e de forma a comunicar com eficácia, os artistas devem criar em liberdade, explorando as inúmeras possibilidades cénicas que têm à sua disposição.

Dentro do próprio teatro não há uma expressão única de linguagem cénica. 0 teatro é ainda muito mais do que nós já hoje conhecemos. As suas possibilidades dentro dos limites do teatro são inesgotáveis e exigem apenas que as imaginações individuais a elas se subordinem. (Negreiros 1993: 152).

É de notar que Almada afirma isto numa época histórica espartilhada pelo Estado Novo, em que os "limites do teatro" não são, grande parte das vezes, os das "imaginações individuais", mas antes os que são impostos pelos ditames da censura. Ao artista cabe, não raro, encontrar um ponto de equilibrio entre os desígnios da sua impulsividade criadora e aquilo que lhe é permitido. Os censores conservam a clara noção do alcance de um espectáculo de teatro e têm consciência das múltiplas transformações do texto dramático na sua passagem para o palco: receiam que os artificios cénicos ou a interpretação 


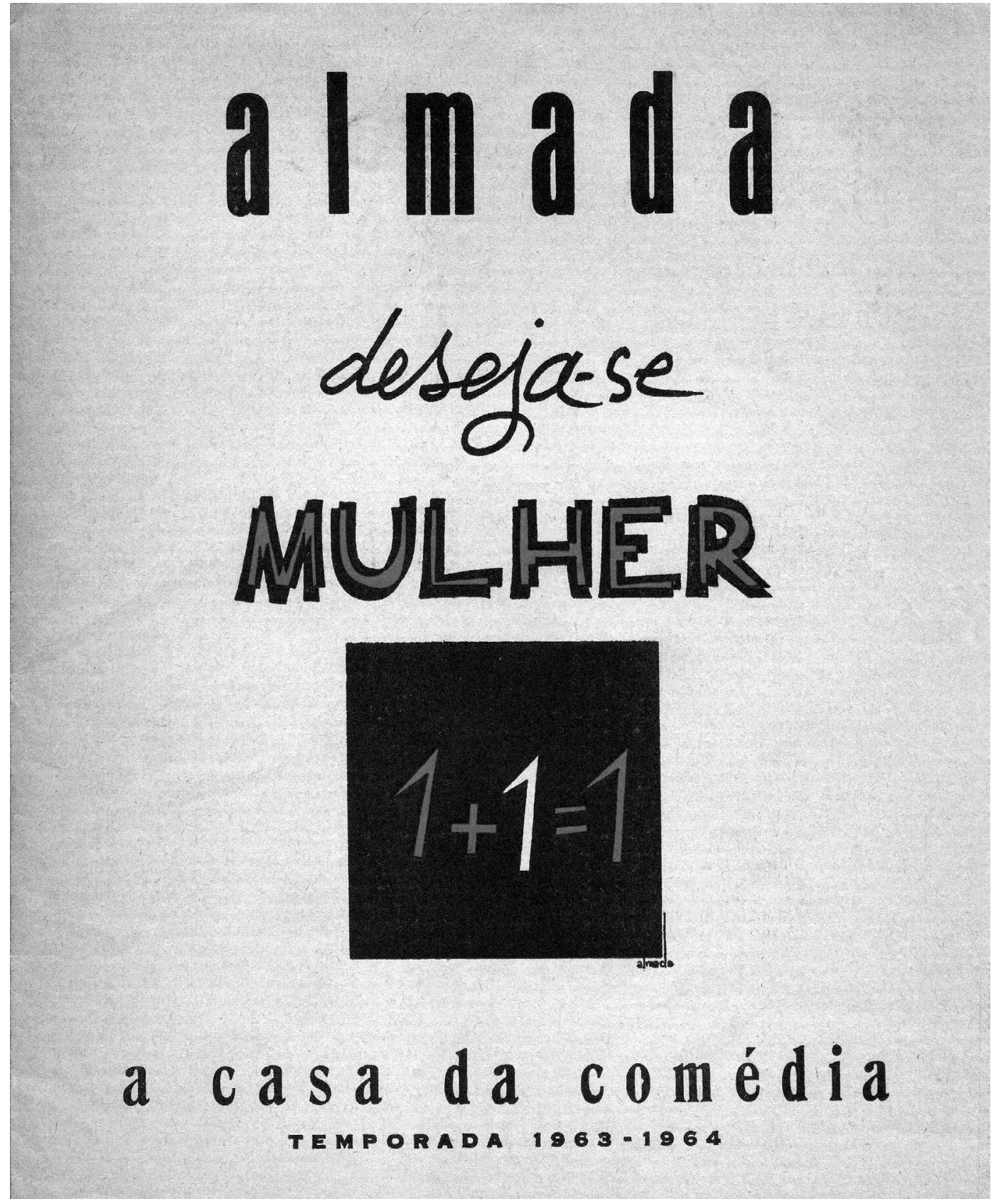

Programa Deseja-se

mulher,

enc. Fernando Amado,

Casa da Comédia, 1963 Herdeiros Almada

do texto possam perverter o que tinham lido, criando significados diferentes ou marcadamente ambiguos. Para além da censura prévia aos textos de teatro, em que se procura anular falas e didascálias com eventuais ofensas à lei ou aos bons costumes, os censores controlam, muitas vezes, a concepção do próprio espectáculo, assistem por norma ao ensaio geral e, caso considerem necessário, impedem a estreia. E este procedimento é regra para todos os textos destinados ao palco, mesmo para os que são escritos e encenados por autores considerados não dissidentes do regime, como Almada Negreiros e Fernando Amado. Em relação às publicações em livro, a censura tinha outro modo de proceder: não fazia o controlo prévio, mas podia impedir a sua comercialização. No que respeita ao livro Deseja-se Mulher, não há qualquer registo anómalo.

No dia 23 de Agosto de 1960, o texto Deseja-se mulher deu entrada nos Serviços da Censura da Inspecção dos Espectáculos. Atribuíram-Ihe o número de registo 6163 e, poucos dias depois, a 6 de Setembro, inscreveramIhe a decisão "Aprovado" - não sem antes Ihe terem aplicado alguns cortes a lápis vermelho e a caneta azul. No carimbo destes serviços pode ainda ler-se que o texto se destinava à "Voz do Operário"; no entanto, não se conhecem quaisquer outras informações sobre este intuito. Proceder ao levantamento dos trechos reprovados permite analisar, por um lado, o nivel de intervenção da censura no texto dramático e, por outro, o conteúdo dessas passagens.

Neste sentido, uma das minhas primeiras preocupações foi perceber se o guião coincidia com o texto publicado ou se, por alguma eventual preocupação com a censura, teria sido adaptado. Não foi. 0 dactiloscrito segue integralmente o livro, com excepção de uma ou outra gralha ou um ocasional erro ortográfico - que, aliás, os censores tiveram o cuidado de corrigir. Através de 


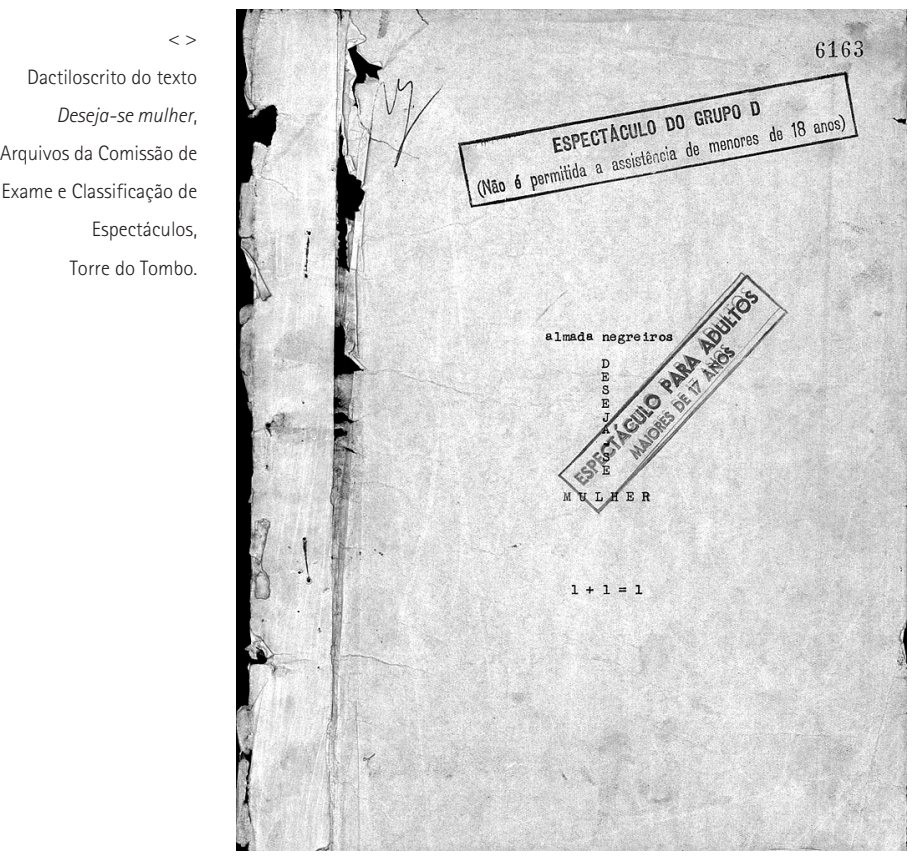

depoimentos orais de alguns dos elementos que integraram o elenco de Deseja-se mulher ${ }^{3}$, fiquei a saber que antes da estreia, a 26 de Novembro de 1963, houve um ensaio aberto ao público que contou com a presença dos censores. Nos arquivos da censura não se encontraram registos escritos desse momento, sabe-se apenas que não houve consequências na prossecução do trabalho apresentado.

Na verdade, Fernanda Lapa, Maria do Céu Guerra e Vitor Silva Tavares são unânimes em considerar que o elemento censura não era particularmente crítico relativamente ao teatro que se fazia na Casa da Comédia. Maria do Céu Guerra assegura:

\footnotetext{
A Casa da Comédia não era um lugar de resistência política. 0 Dr. Fernando Amado era um monárquico da via democrática. Pertencia a um grupo, mas não era um perseguido. E o Almada também não. $\mathrm{Na}$ Casa da Comédia não se passava o sobressalto que acontecia noutros lugares: como no Teatro Moderno, no Teatro Estúdio de Lisboa, no Teatro Experimental do Porto e, durante algum tempo, no Teatro Experimental de Cascais. No entanto, tínhamos censura, claro. Houve ensaio de censura, mas não houve nenhum corte. Eles estiveram presentes, mas, que me lembre, não aconteceu nada. (Conversa com Maria do Céu Guerra 2011)
}

Com efeito, se os censores receavam que a encenação tivesse dado um sentido "perigoso" às falas, seguramente ficaram mais descansados, depois de assistirem ao ensaio Podemos imaginá-los, na Casa da Comédia, a segurar o dactiloscrito, olhando atentamente para as passagens riscadas, para os parágrafos sublinhados, para os pontos de interrogação desenhados à margem e para as notas com a palavra "Atenção", à espera do momento flagrante para intervir. No final, sem nada para apontar à encenação nem ao desempenho do elenco, permitiram que o espectáculo acontecesse. E, assim, Deseja-se mulher pôde estrear, com aplausos e críticas de imprensa bastante elogiosas.

Maria do Céu Guerra acrescenta o relato de um episódio quase burlesco, mas que expressa bem o ambiente de liberdade criadora e de entrega à arte que se vivia naquele grupo dirigido por Fernando Amado:

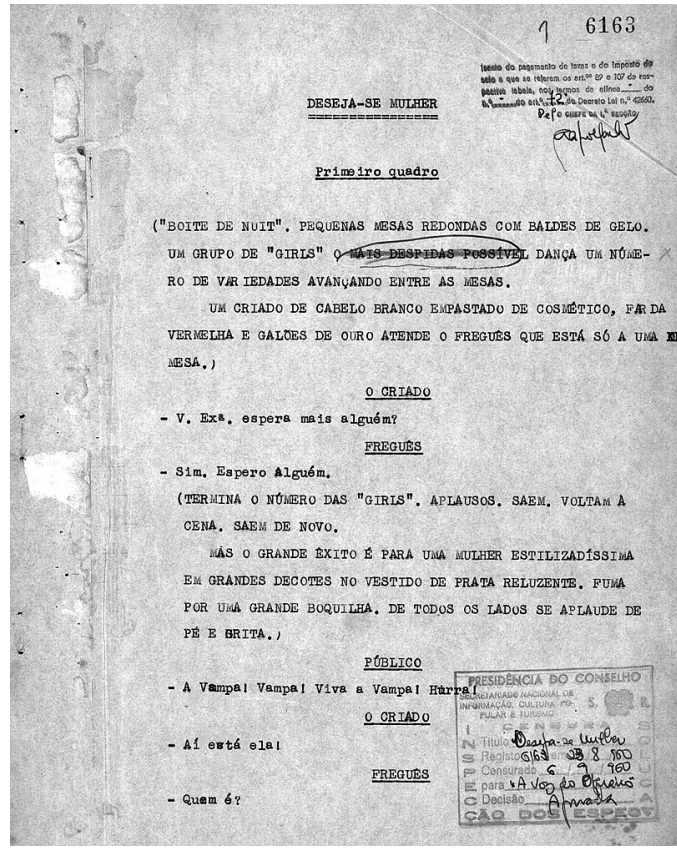

$\mathrm{Na}$ Casa da Comédia havia um PIDE [um informador] - era o Alberto, o nosso electricista. Os rapazes começaram a desconfiar. Viam-no sair e ir para lugares suspeitos. Como o Dr. Fernando Amado tinha sempre em consideração o que as meninas the diziam, os rapazes pediram-nos para falarmos com ele. E assim o fizemos:

- Ó Dr. Fernando, olhe que o Alberto é um PIDE.

- Ai é? Então, esperem que eu vou lá falar com ele.

Eu, a Fernanda Lapa e a Zita Duarte pusemo-nos à espreita atrás da porta, que era uma porta de saloon. Não estávamos a faze nada de mal, afinal aquela era a nossa casa e só queriamos o bem da nossa casa.

0 Dr. Fernando sentou-se na beira de uma secretária, apoiandose num chapéu-de-chuva e, pausadamente, dirigiu-se ao Alberto:

- Fiquei a saber, não me pergunte como, que o menino faz parte da PIDE. Pois saiba o menino que o Teatro é um espaço de Liberdade. Esta é uma casa de Liberdade. Ora, um espaço de Liberdade não se coaduna com a policia, muito menos com a PIDE. 0 menino ou fica no Teatro ou vai para a PIDE. Tem de escolher!

Ele tratou-o por menino, como tratava toda a gente, e o Alberto já deveria ter quarenta e tal anos! 0 que é certo é que 0 Alberto nunca mais apareceu no teatro. Mas nós também não tivemos qualquer problema com a PIDE. (Ibid.)

Segundo os testemunhos recolhidos, não houve contrariedades nem com a PIDE, nem com a censura Mesmo estando todos conscientes da sua existência, isso parecia não afectar em nada a imaginação e a liberdade criativa dos artistas.

A preparação do espectáculo decorreu com toda a normalidade e, embora houvesse elementos muito jovens no grupo, não foi preciso chamar a atenção para o sistema limitador da censura, como lembra Vitor Silva Tavares:

"Em todas as conversas que tivemos, não apareceu nunca o elemento censura. Nada disso".

Fernanda Lapa evoca um dos primeiros ensaios de Deseja-se mulher, em que o encenador terá dito para riscarem algumas passagens - muito provavelmente, as que tinham sido cortadas pela censura. Na memória, ficou-lhe apenas um dos cortes. 


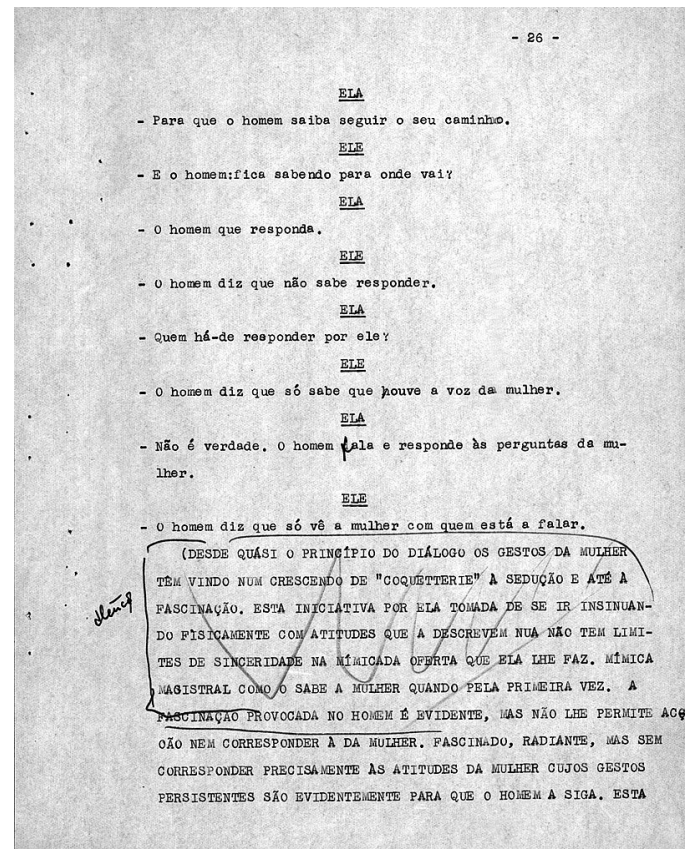

Lembro-me de uma passagem em que a Céu Guerra, que fazia a personagem Mulher, dizia à Vampa (que era eu), qualquer coisa assim: "Aquela que vivia com o do Ministério.... Corta! E cortou-se a palavra "Ministério". (Conversa com Fernanda Lapa 2011)

Com efeito, o corte a que se referiu Fernanda Lapa conta-se entre os que fazem parte do documento localizado na Torre do Tombo. Na fala citada, elimina-se uma referência clara a um conteúdo relacionado com um órgão estatal, ainda que não tivessem sido referidos um nome ou um cargo específicos. Dentro do mesmo assunto - política -, o texto sofreu um outro corte, numa referência aos grandes capitalistas, considerada subversiva ou demasiado jocosa: "colossos milionários que têm o mundo nas mãos e a alta finança a seus pés". À semelhança do corte anterior, não se nomeiam figuras especificas.

Os censores também perscrutavam sempre com muita atenção qualquer referência à Igreja. Neste caso, cortaram uma didascália da personagem Anjo da Guarda: "Atrás do Protagonista, um Anjo da Guarda como nas estampas de infância e com casaco curto. Faz com enfado os mesmos movimentos do protagonista. Este decide-se por onde disse o sinaleiro, mas antes de sair pára" - curiosamente, o traço vermelho chegou até à última palavra da página, que não coincidia com a última da frase, mas para a censura era o bastante para impedir que a figura do Anjo fizesse gestos desapropriados à sua condição divina.

Por fim, registamos aquele que, neste documento, foi o tema mais fustigado pelo lápis vermelho: a obscenidade ou o que poderia ser tomado por tal. Todas as expressões ofensivas das boas condutas, ou que remetessem para assuntos considerados "vulgares", foram riscadas e, em algumas situações, assinaladas com a palavra "Atenção" - muitas delas nas didascálias, o que reforça, precisamente, a função de controlo que se pretendia exercer sobre o trabalho de encenação e de direç̧ão de actores. 0 que não é dito pode ser insinuado em palco - e a censura estava consciente disso. Assim, todas as alusões de teor impudico ou moralmente ofensivas foram censuradas neste texto.

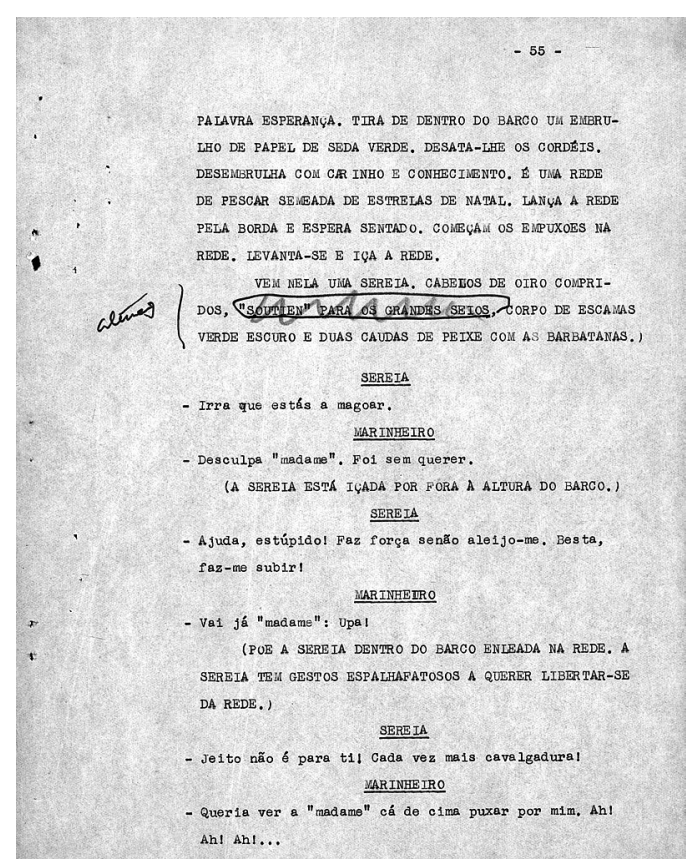

$<>$

Dactiloscrito do texto

Deseja-se mulher

Arquivos da Comissão de Exame e Classificação de Espectáculos,

Torre do Tombo.
0 primeiro destes cortes dá-se logo na página inicial do guião, na didascália de abertura: "o mais despidas possivel". Aqui, procura-se claramente evitar que o "Grupo de 'Girls'" surja em cena de forma menos própria...

Mais adiante, na página 38 do guião, corta-se uma passagem na fala da personagem Ele, por conter claramente alusões sexuais: "Tu mesma capaste em ti a tua perfectibilidade. Castrada de amor, não de sexo. A ânsia de amor não morrerá em ti, e em ti o amor ficará sempre adiado". Ainda na mesma personagem, mas já na página 53, os censores cortaram a seguinte expressão: "Fiquei logo isento de lutas de sexo". A presença da palavra "sexo" ou a estranheza da remissão para "lutas de sexo" terão estado na origem deste corte.

Quase no final do guião de Deseja-se mulher, foi traçado o último risco. Desta feita, sobre a didascália que descreve fisicamente a personagem Sereia: " 'soutien' para os grandes seios". Simultaneamente, é feita uma advertência lateral - Atenção -, sugerindo novamente um controlo presencial.

Perante este último corte, salta a inevitável interrogação: mas afinal, como se apresentou a Sereia no espectáculo? Vitor Silva Tavares, responsável pelos figurinos, recorda prontamente:

Com grandes seios! Lembro-me de Ihe ter posto dois seios enormes, duas bolas. Com o Almada nunca poderiam ser os seios naturais. Era uma coisa enorme, porque para o Almada tinha de ser tudo enorme. Lá nisso era tipo Fellini.

E a Sereia, que já era um pouco gorda, ficava com um recorte visual enorme. Mas tudo isto ia muito ao encontro da visão do Mestre. (Conversa com Vitor Silva Tavares 2011)

E a visão dos censores era, seguramente, bem diferente da visão de Almada. As palavras de Vitor Silva Tavares sobre o figurino da Sereia permitem compreender que os receios manifestados pela censura eram completamente infundados. Ao "Mestre" não interessavam as imagens realistas, mas tudo aquilo que pudesse criar deslumbramento. 
Possivelmente, quando Almada viu este último corte, e todos os que foram feitos nas didascálias, não se preocupou - a solução estava já encontrada, a censura é que não tinha entendido o seu teatro.

Também as passagens cortadas no discurso directo não ofereceram dificuldades, nem ao autor, nem ao encenador do texto. 0 que foi cortado não foi dito. Porém, o sentido do texto manteve-se, mesmo com os cortes.

Não deixa de ser curioso salientar que Deseja-se mulher recebeu o carimbo de "Espectáculo para adultos" e, mesmo assim, sofreu todos os cortes referidos. Na capa do guião, lêem-se as restrições: "Espectáculo do Grupo D (Não é permitida a assistência de menores de 18 anos)" e "Espectáculo para Adultos; maiores de 17 anos".

À luz dos nossos dias, poderíamos ser levados a pensar que os espectáculos classificados para adultos seriam mais permissivos em termos de conteúdos... Estas medidas censórias coadunavam-se com os procedimentos da época, de forma a garantir a integridade moral e a impedir a propagação de "más condutas" nos espectadores. 0 zelo dos serviços de censura estendia-se a toda a população, independentemente, da faixa etária a que se destinasse 0 espectáculo. Com cortes e carimbos, o texto estava aprovado. Deseja-se mulher podia passar para o palco.

\section{Referências bibliográficas}

ALMADA NEGREIROS, José de (s/d), A Radiotelefonia e o teatro: Palestra radiofónica pela Emissora Nacional, texto dactilografado, Espólio Almada Negreiros (não publicado).

-- (1959), Deseja-se mulher, Lisboa, Editorial Verbo.

-- (1992a), "Encorajamento à Juventude Portuguesa para o Cinema e para o Teatro" [1935], Ensaios, Vol. V, Lisboa, Imprensa Nacional-Casa da Moeda, , pp. 131-135

_- (1992b) "O Pintor do Teatro" [1948], Ensaios, Vol. V, Lisboa, Imprensa Nacional-Casa da Moeda.

-- (1993) "Noticia sobre um acto de teatro que a seguir se publica" [1935], Teatro, Vol. VII, Lisboa, Imprensa Nacional-Casa da Moeda, pp. 151153.
-- (2006), "Pierrot e Arlequim" [1924], Manifestos e conferências, Lisboa, Assírio \&t Alvim, pp. 97-131.

Anon. (1960), "A Voz do Operário", Gazeta Musical e de Todas as Artes, Lisboa, Janeiro, Fevereiro, p. 3

VITORINO, Orlando (1964), "Semanário do Espectador: Teatro de Almada Negreiros", Diário de Notícias, 16-01-1964, pp. 13 e 14.

\section{Fontes orais}

Conversa com Vitor Silva Tavares (Silvia Laureano Costa, entrevistadora), Lisboa, 23 de Junho de 2011 (texto transcrito do áudio; inédito). Conversa com Fernanda Lapa (Sílvia Laureano Costa, entrevistadora), Lisboa, 23 de Julho de 2011 (texto transcrito do áudio; inédito). Conversa com Maria do Céu Guerra (Silvia Laureano Costa, entrevistadora), Lisboa, 8 de Julho de 2011 (texto transcrito do áudio; inédito). 